\title{
HEATS OF COMBUSTION OF SOME SYMMETRICAL DIALKYL UREAS AND THEIR CORRESPONDING
}

\section{ALKYL CARBAMATES}

\author{
By T. Venugopala Charlu and M. R. A. Rao, F.A.Sc. \\ (Department of Inorganic and Physical Chemistry, Indian Institute of Science, Bantgalore-12, India)
}

Received May 15, 1964

\begin{abstract}
The standard heats of combustion of the disubstituted ureas, $\mathrm{N}, \mathrm{N}^{\prime}$ diheptyl urea, $\mathrm{N}, \mathrm{N}^{\prime}$-dioctyl urea and $\mathrm{N}, \mathrm{N}^{\prime}$-didecyl urea and the carbamates, $n$-heptyl ammonium $n$-heptyl carbamate, $n$-octylammonium $n$-octyl carbamate and $n$-decyl ammonium $n$-decyl carbamate have been determined. The values found are $2353 \pm 1 \cdot 3,2658 \cdot 4 \pm 1 \cdot 1,3268 \cdot 5 \pm 1 \cdot 7,2349 \cdot 8 \pm$ $1 \cdot 6,2654 \cdot 4 \pm 1 \cdot 2,3264 \cdot 6 \pm 1 \cdot 8, \mathrm{~K}$.cals. mole ${ }^{-1}$ respectively. The heats of formation of these compounds have been calculated.
\end{abstract}

LACK of data on the heats of formation of symmetrical $\left(\mathrm{N}, \mathrm{N}^{\prime}\right)$ dialkyal ureas and their respective alkyl ammonium alkyl carbamates has greatly hampered the calculation of the thermodynamic data of the reactions by which these compounds are produced. To evaluate the heats of formation of these compounds precise and accurate measurements of the heats of combustion are required. The present investigation reports experimental data on the heats of combustion of the ureas, $\mathbf{N}, \mathbf{N}^{\prime}$-diheptyl urea, $\mathbf{N}, \mathbf{N}^{\prime}$-dioctyl urea, $\mathrm{N}, \mathrm{N}^{\prime}$-didecyl urea and the carbamates heptyl ammonium heptyl carbamate, octyl ammonium octyl carbamate and decyl ammonium decyl carbamate. The heats of formation of these compounds have also been calculated.

\section{METHOD AND APPARATUS}

The heats of combustion of the compounds were determined by the combustion of the solid ureas and the carbamates in the form of pellets in an oxygen bomb calorimeter. ${ }^{1}$ The procedure followed is similar to that described in A.S.T.M. Standards ${ }^{2}$ and by Dickinson. ${ }^{3}$ The sample was weighed in a nickel crucible and placed in the loop electrode. One millilitre of water was added to the bomb and the bomb was filled with oxygen to 25 atmospheric pressure at $25^{\circ} \mathrm{C}$. The sample was ignited by means of a fuse wire coiled above the sample. The thermometers employed in the measurement of temperature were of the range $65-90^{\circ} \mathrm{F}$. graduated in 
units of $0.05^{\circ} \mathrm{F}$. and provided with correction charts for scale correction. The temperature was read correct to $0.005^{\circ} \mathrm{F}$. by suitable magnification. The corrections for thermal leakage, for the formation of nitric acid and the combustion of the fuse wire are applied by adopting the procedure given in the Manual of the Parr Instrument Company. ${ }^{1}$ The energy equivalent of the calorimeter system was determined by employing benzoic acid as the standard substance. Five calorimetric experiments were made with each of the samples. The mean value and the average deviation from the mean are given in Table II. After the combustion there was no carbon left in the bomb indicating the completeness of the combustion.

\section{MATERIALS}

(a) Substituted ureas.-The substituted ureas are synthesised by the high pressure reaction of carbon dioxide with the corresponding primary amine." They were purified by recrystallisation from aqueous ethyl alcohol and dried over phosphorus pentoxide under reduced pressure.

(b) Carbamates. -The carbamates ${ }^{5}$ are obtained by passing dry carbon dioxide into an etherial solution of the amine maintained at $0^{\circ} \mathrm{C}$. The crystalline carbamate obtained was washed with fresh portions of dry ether to remove any unreacted amine and preserved in a desiccator over phosphorus pentoxide.

Amines.-The amines employed ( $n$-heptyl, $n$-octyl and $n$-decyl amines) are prepared by the "Schmidt reaction ${ }^{8}$ " and purified by standard methods.

The results of the microcombustion analysis and the melting points of the ureas and carbamates are given in Table I which indicate that the samples are quite pure.

\section{EXPERIMENTAL RESUltS}

The results of the heats of combustion of the ureas and carbamates are listed in Table II. The values of the heats of combustion at constant volume, $\triangle E_{c}{ }^{\circ}$ in K.cals. mole ${ }^{-1}$ at $25^{\circ} \mathrm{C}$. are given in column 3 of Table II. These are converted to the corresponding values at constant pressure, $\triangle \mathrm{H}_{c}^{\circ}$ by employing the relation,

$\triangle \mathrm{H}_{\mathrm{c}}{ }^{\circ}=\Delta \mathrm{E}_{c}{ }^{\circ}+\triangle n \mathrm{RT}$ where $\triangle n$ is the increase in the number of moles of gas in the system. The last column contains values of the standard heats of formation from the elements, $\triangle \mathrm{H}_{f}{ }^{\circ}$, calculated from the heats of combustion, $\Delta \mathbf{H}_{\mathbf{c}}{ }^{\circ}$, with the aid of the values of the heats of formation of carbon 
dioxide and liquid water. ${ }^{10}$ The heat of combustion $\Delta \mathbf{E}_{\mathfrak{c}}{ }^{\circ}$, for instance in the oxidation of $N, N^{\prime}$-diheptyl urea refer to the reaction,

$$
\mathrm{C}_{15} \mathrm{H}_{32} \mathrm{~N}_{2} \mathrm{O}+22 \frac{1}{2} \mathrm{O}_{2} \rightarrow 15 \mathrm{CO}_{2}-16 \mathrm{H}_{2} \mathrm{O}+\mathrm{N}_{2}
$$
$(s)$
$(g)$
(g)
$(l)$
$(g)$

The heat of formation refer to the reaction,

$$
15 \mathrm{C}+16 \mathrm{H}_{2}+\mathrm{N}_{2}+\frac{1}{2} \mathrm{O}_{2} \rightarrow \mathrm{C}_{12} \mathrm{H}_{32} \mathrm{~N}_{2} \mathrm{O}
$$
$(s)$
(g)
(g)
$(g)$
$(s)$

TABLE I

\begin{tabular}{|c|c|c|c|c|}
\hline \multirow[b]{2}{*}{ Compound } & \multicolumn{2}{|c|}{ Melting point ${ }^{\circ} \mathrm{C}$} & \multicolumn{2}{|c|}{ Microcombustion analysis } \\
\hline & Observed & $\begin{array}{l}\text { Litera- } \\
\text { ture } \\
\text { value }\end{array}$ & Found $(\%)$ & $\begin{array}{c}\text { Theorei- } \\
\text { tical } \\
(\%)\end{array}$ \\
\hline $\begin{array}{l}\mathrm{N}, \mathrm{N}^{\prime} \text {-Diheptyl urea } \\
\left(\mathrm{C}_{7} \mathrm{H}_{\mathbf{1 5}} \mathrm{NH}\right)_{\mathbf{2}} \mathrm{CO}\end{array}$ & $91 \cdot 0$ & $91 \cdot 0^{7}$ & $\begin{array}{l}\mathrm{C}=69 \cdot 72 \\
\mathrm{H}=12 \cdot 92 \\
\mathrm{~N}=11 \cdot 0\end{array}$ & $\begin{array}{l}\mathrm{C}=70 \cdot 31 \\
\mathrm{H}=12 \cdot 51 \\
\mathrm{~N}=10 \cdot 93\end{array}$ \\
\hline $\begin{array}{l}\mathrm{N}, \mathrm{N}^{\prime} \text {-Dioctyl urea } \\
\left(\mathrm{C}_{8} \mathrm{H}_{17} \mathrm{NH}\right)_{2} \mathrm{CO}\end{array}$ & $90 \cdot 0$ & $89-90^{8}$ & $\begin{array}{l}\mathrm{C}=72 \cdot 14 \\
\mathrm{H}=12 \cdot 29 \\
\mathrm{~N}=9 \cdot 78\end{array}$ & $\begin{array}{l}\mathrm{C}=71 \cdot 76 \\
\mathrm{H}=12 \cdot 76 \\
\mathrm{~N}=9 \cdot 85\end{array}$ \\
\hline $\begin{array}{l}\mathrm{N}, \mathrm{N}^{\prime} \text {-Didecyl urea } \\
\left(\mathrm{C}_{\mathbf{1 0}} \mathrm{H}_{\mathbf{2 1}} \mathrm{NH}\right)_{\mathbf{2}} \mathrm{CO}\end{array}$ & $95 \cdot 0$ & $\begin{array}{l}95-97^{8} \\
94-95^{9}\end{array}$ & $\begin{array}{l}\mathrm{C}=73 \cdot 58 \\
\mathrm{H}=12 \cdot 72 \\
\mathrm{~N}=8 \cdot 03\end{array}$ & $\begin{array}{l}\mathrm{C}=74 \cdot 03 \\
\mathrm{H}=12 \cdot 9 \\
\mathrm{~N}=8 \cdot 2\end{array}$ \\
\hline $\begin{array}{l}n \text {-Heptyl ammonium } \\
\text { n-Heptyl carbamate } \\
\left(\mathrm{C}_{7} \mathrm{H}_{15} \mathrm{NH} \mathrm{CO} \mathrm{NH} \mathrm{C}_{7} \mathrm{H}_{15}\right)\end{array}$ & $82 \cdot 0$ & $82-84^{10}$ & $\begin{array}{l}\mathrm{C}=65 \cdot 92 \\
\mathrm{H}=12 \cdot 87 \\
\mathrm{~N}=10 \cdot 59\end{array}$ & $\begin{array}{l}\mathrm{C}=65 \cdot 64 \\
\mathbf{H}=12 \cdot 48 \\
\mathrm{~N}=10 \cdot 21\end{array}$ \\
\hline 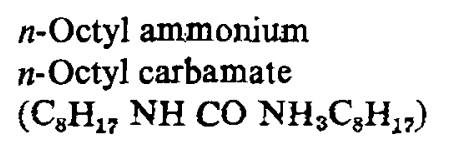 & $86 \cdot 0$ & $84-86^{10}$ & $\begin{array}{l}\mathrm{C}=67 \cdot 53 \\
\mathrm{H}=13 \cdot 11 \\
\mathrm{~N}=9 \cdot 57\end{array}$ & $\begin{array}{l}\mathrm{C}=67 \cdot 48 \\
\mathrm{H}=12 \cdot 66 \\
\mathrm{~N}=9 \cdot 26\end{array}$ \\
\hline $\begin{array}{l}n \text {-Decyl ammonium } \\
n \text {-decyl carbamate } \\
\left(\mathrm{C}_{10} \mathrm{H}_{21} \mathrm{NH} \mathrm{CO} \mathrm{NH} \mathrm{C}_{10} \mathrm{H}_{21}\right)\end{array}$ & $89 \cdot 0$ & $90 \cdot 0^{11}$ & $\begin{array}{l}\mathrm{C}=70.41 \\
\mathrm{H}=12.88 \\
\mathrm{~N}=7.9\end{array}$ & $\begin{array}{l}\mathrm{C}=70 \cdot 33 \\
\mathrm{H}=12 \cdot 92 \\
\mathbf{N}=7 \cdot 81\end{array}$ \\
\hline
\end{tabular}

Melting points and microcombustion data

N.B.-Superscripts indicate the reference numbers. 
TABLE II

Heats of combustion of substituted ureas and carbamates referring to the solid state at $25^{\circ} \mathrm{C}$.

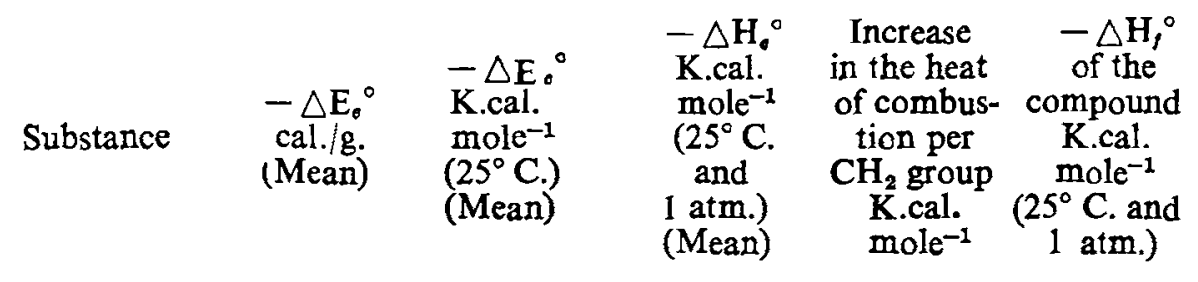

1. $\mathrm{N}, \mathrm{N}^{\prime}$-Diheptyl $9164 \pm 5 \quad 2350 \pm 1 \cdot 3 \quad 2353 \pm 1 \cdot 3$ urea

$152 \cdot 3$

$150 \cdot 0$

2. $\mathrm{N}, \mathrm{N}^{\prime}$-Dioctyl $\quad 9326 \pm 4 \quad 2654 \pm 1 \cdot 1 \quad 2658 \cdot 4 \pm 1 \cdot 1$

$170 \cdot 2$ urea (Compound $1+$ $2 \mathrm{CH}_{2}$ )

$152 \cdot 5$

3. $\mathrm{N}, \mathrm{N}^{\prime}$-Didecyl $\quad 9579 \pm 5 \quad 3263 \pm 1 \cdot 7 \quad 3268 \cdot 5 \pm 1 \cdot 7$ $209 \cdot 4$ urea (Compound $2+$ $\left.4 \mathrm{CH}_{2}\right)$

4. $n$-Heptyl $\quad 8549 \pm 6 \quad 2346 \pm 1.6 \quad 2349.8 \pm 1.6$ $222 \cdot 2$ ammonium $n$-heptyl carbamate

$152 \cdot 3$

5. $n$-Octylammo- $8758 \pm 4 \quad 2650 \pm 1 \cdot 2 \quad 2654 \cdot 4 \pm 1 \cdot 2$ $242 \cdot 5$ nium $n$-octyl carbamate (compound $\left.4+2 \mathrm{CH}_{2}\right)$

6. $n$-Decyl ammo- $9088 \pm 5 \quad 3259 \pm 1 \cdot 8 \quad 3264 \cdot 6 \pm 1 \cdot 8$ $282 \cdot 8$ nium $n$-decyl carbamate (compound $\left.5+4 \mathrm{CH}_{2}\right)$

$$
\text { Mean }=\overline{152 \cdot 4}
$$




\section{CoNCLUSION}

It is seen from Table II that the average increase in the heat of combustion, $\triangle \mathrm{H}_{\mathrm{c}}{ }^{\circ}$, per $\mathrm{CH}_{2}$ group in the hydrocarbon chain of the urea derivatives and the respective carbamates is $152.4 \mathrm{~K}$.cals. corresponding to the value of $156 \cdot 3^{11} \mathrm{~K}$.cals. observed in the homologous series of paraffin hydrocarbons. Since the increase in the heat of combustion per $\mathrm{CH}_{2}$ group has attained a constant value of $152.4 \mathrm{~K}$.cals, data for the heats of combustion of the higher substituted ureas and carbamates could be obtained by the addition of the proper multiple of the above value to the heat of combustion of the preceding compound.

\section{REFERENCES}

1. Manual No. 117, Parr Oxygen Bomb Calorimeters, Parr Insirument Company, Illinois.

2. A.S.T.M. Standards, 1949, Part 5, p. 605.

3. Dickinson, H. C. _. Bull. Natl. Bur. Standards, 1915, 11, 189.

4. Venugopala Charlu, T. .. "Studies on high pressure reactions, (a) Aliphatic amines and carbon dioxide, (b) 1-4 dioxane, carbon monoxide and water," Ph.D. Thesis, Indian Institute of Science, Bangalore, 1962.

5. Moore, M. B. and Wright, J. Am. Chem. Soc., 1948, 70, 3865.

H. B.

6. Org. Reactions, Ed. Roger Adams et al., John Willey and Sons, Inc., 1947, 3, 307.

7. Chabrier, P. and Najer, H. Bull. Soc. Chim. France, 1957, 2, $1069-072$.

8. Fred Applegath et al. . . Brit. Pat. 818,864 (To Monsanto Chemical Co.), 26 Aug. 1959; Chem. Abstr., 1960, 54, 9774.

9. Scott, F. L. and Scott, J. Am. Chem. Soc., 1957, 79, 6081. M. T.

10. Hunter, B. A. and Glenn, U.S. Pat. 2,635,124 (To United States Rubber Co.), April 14, H. D. 1953; Chem. Abstr., 1953, 47, 7814.

11. Leibnitz, E. et al.; $\quad$. Chem. Abstr., 1961, 55, 365.

12. Lange, N. A. _ Handbook of Chemistry, McGraw-Hill Book Co., Inc., New York, 1956.

13. Prosen, E. J. and Rossini, J. Research, Natl. Bur. Standards, 1945, 34, 263. F. D. 